November issue. The Journal is fortunate, however, in now having Professor Harold Jeffreys, F.R.S., on the Editorial Board.

It is impossible at present to give statistics for the numbers of subscribers to the Journal, but the publishers, Messrs. Thomas Nelson \& Sons, Ltd., are satisfied with the progress made. The greater proportion of the subscribers are naturally British but Americans are giving good and growing support and so are a number of continental countries, and four copies regularly pass across the Iron Curtain into Russia. Judging by notices that have appeared in a number of philosophical and scientific journals published in Great Britain, on the Continent and in the U.S.A., and by private comments and correspondence, the Journal is being well received, indeed warmly welcomed, by that section of the learned public for which it is intended. Moreover, contributions are now being regularly sent to the Editor not only from writers living in these islands, but also from lands as distant as Australia and South Africa, as well as from the U.S.A. The Journal shows every possibility of becoming, and in many quarters seems expected to become, an institution that could exert a unique, profound and much desired influence on contemporary scientific thought.

The only slightly disappointing aspect of the support given to the Journal is that appreciably less than half of the members of the Group have taken out subscriptions. It is much to be desired that this will have been set right by the next Annual General Meeting.

Finally, it is of interest to give some figures to show the gradual expansion of the Group. At.present the Group contains 156 members as compared with 134 on 6th March, 1950, making an increase of 22.

\title{
Science without Properties
}

By Professor J. H. WOODGER

ABSTRACT of Chairman's Address, delivered at the Annual General Meeting held on 5th March, 1951

After briefly pointing out some of the obscurities attaching to the notion of property, and especially to the notion of a thing having properties and its linguistic correlate the antithesis between subject and predicate, Professor Woodger proceeded to show how a language for natural science (called WL) could be constructed which would avoid these difficulties. This language contains two kinds of signs: (1) names, and (2) operation signs. The latter are either signs of operations on names, by which new names are constructed, or signs of operations on statements by which new statements are constructed. Three simple syntactical rules suffice to define "statement in WL". The simplest statements are formed by the juxtaposition of two names; the remaining statements are those resulting from the application of the operations mentioned to these simple statements. Three simple semantical rules suffice to define " true statement in WL". A simple statement is true if everything named by the first or left-hand name is also named by the second or right-hand of its two juxtaposed names. Thus although names are distinguishable according to the number of objects which they name, no distinction into subjects and predicates is made. From the grammatical point of view all the names in WL are nouns. Professor Woodger pointed out some of the problems which remain to be solved, in particular the problem of how to introduce mathematics into such a language. 